\title{
Aircraft Design Optimization Process using a Decision Model by Database*
}

\author{
Hsu Myat Naing, Nhu Van Nguyen, Jae-Woo Lee, and Sangho Kim \\ Aerospace Information Engineering, Konkuk University, Seoul 143-701, Korea
}

\begin{abstract}
In this study, an efficient methodology capable of systematically constructing an aircraft design database is developed and its application is discussed. The database focuses on fighter and attack aircraft because their design is a particular challenge compared with the design of other types of aircraft. For small conventional aircraft, historical information accumulated over many years on countless previous designs is freely available to designers. Such data for fighter aircraft design are, however, difficult to obtain or are insufficient. The database developed can contribute to the design of fighter and attack aircraft on a conceptual level. In addition, decision-making models are developed by means of data mining as well as approximation models based on the developed database to facilitate initial aircraft configuration decisions. The efficiency and simplicity of the proposed method are described in a case study, which also describes a sample process of conceptual design optimization using initial design information extracted from the developed database.
\end{abstract}

Key Words: Response Surface Methodology, Data Mining, Decision Model, Database, Optimization

\section{Introduction}

The designing of aircraft is an inherently complex process. Numerous methodologies, tools and software packages are available for aircraft design. Advanced design methodologies have led to significant increases in computation cost and time as the level of complexity of the analysis tool increases. These depend on many factors such as customer and manufacturer demand, safety protocols, accuracy level, etc. The design process starts with the aircraft's intended purpose. Aircraft performance requirements differ according to the purpose for which they are intended. In the case of aircraft design, engineers try to envision all the possible decisions that must be made during each design phase and how they are affected by the various performance targets and applications the aircraft will be required to fulfill. These design decisions should be made by an expert designer who knows the advantages and disadvantages of each. The complex interaction between design decisions, their justification and their influence on other aspects of design must be modeled accurately, covering as broad a base as possible to handle diverse mission goals. For this reason, aircraft design is quite a complex and lengthy process. There is a need to build a model to assist decision-making by designers to reduce complexity and save time. Two such techniques are data mining, which derives useful information and relationships between data from a database, and the response surface methodology (RSM) approximation technique, both of which are applied in the construction of decision models in this study. ${ }^{1-4)}$ As a consequence, there is a need for a large amount of information. Databases are set up to allow users to access data efficiently. They are created for various purposes and applied in different ways. Development of ad-

(C) 2015 The Japan Society for Aeronautical and Space Sciences

*Received 10 January 2014; final revision received 4 April 2014; accepted for publication 14 May 2014. equate databases and their efficient application are increasingly required.

This study describes the efficient application of a database using a decision-making model for aircraft design which also describes a process of conceptual design optimization using an initial design derived from decision-making models. This design process is especially focused on fighter and attack aircraft because of the difficulty of obtaining adequate data at reasonable cost, whereas general specifications for commercial aircraft are widely available.

\section{Process and Methodology}

The approach introduced in this study begins with the systematic construction of an aircraft database. It is developed in stages by using insufficient information from open sources and public sources. Additionally, approximation models and sensitivity analysis are implemented and applied to predict missing data in the database. ${ }^{5-7)}$ Analysis methods are developed for aerodynamics, propulsion and performance. ${ }^{8-10)}$ These analysis codes are implemented in a spreadsheet using the well-known Visual Basic for applications (VBA) programming language for simple and efficient calculation. ${ }^{11-13)}$ The developed database contains complete information for 43 different types of fighter and attack aircraft. The process can predict complete information for new aircraft from partial information.

The next step in the methodology is the efficient application of the developed database. Decision-making models are constructed based on the database using data mining and approximation techniques. ${ }^{14)}$ The implemented decision models provide an initial design configuration of new aircraft concepts based on a set of performance requirements. After that, a design optimization process is set up using these initial design configurations. An overview of the process is described in Fig. 1. 


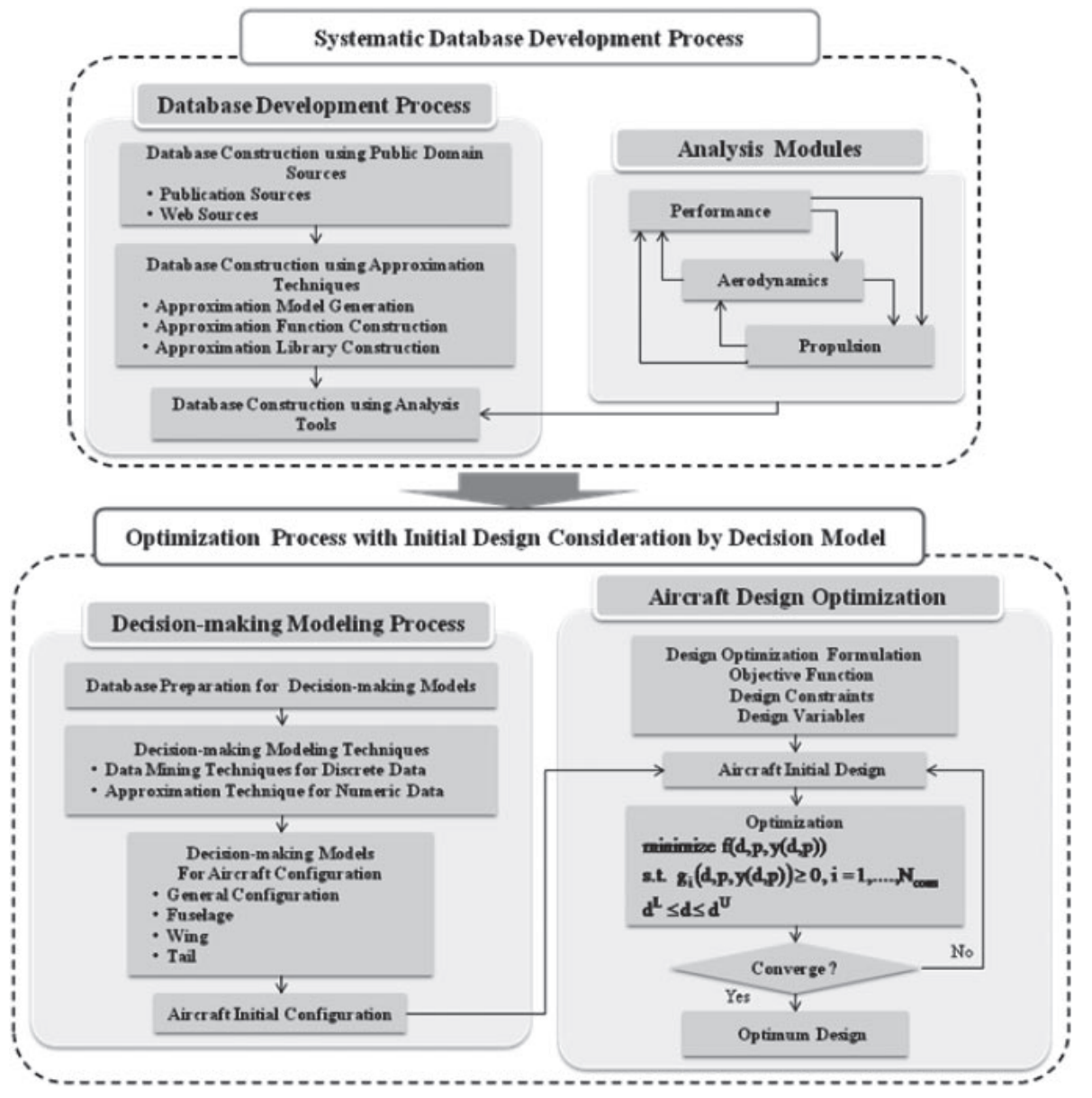

Fig. 1. Aircraft design process in database development.

\section{Systematic Database Development Process}

In the database development process, the implementation steps are classified according to the data available for fighter and attack aircraft. A parameter-based database development process is used. The main three steps are set up as follows:

- database construction using public domain sources

- database construction using approximation technique

- database construction using analysis tools

The detailed process of database development can be seen in Fig. 2. In this figure, the left-hand side describes the database development and the right-hand side the application process of the implemented database.

\subsection{Database construction from public domain sources}

The basic configuration database for 43 aircraft was constructed according to the first step of the database construction process. The configuration data for fighter and attack aircraft was collected as much as possible from public domain sources and publications. The utilized publications included Jane's All the World's Aircraft, ${ }^{15)}$ The World's Great Attack Aircraft ${ }^{16)}$ The Illustrated Directory of Fighters, ${ }^{17)}$ and An Illustrated Guide to Modern Fighters and Attack Aircraft. ${ }^{18)}$ Various types of aircraft were included in the database.

\subsection{Database construction using approximation tech- nique}

A preliminary database was developed from public do- main sources and publications. In many cases, insufficient data was available to fully populate every attribute of a given aircraft. The missing data was estimated using RSM-based approximation.

RSM is an empirical modeling approach using polynomials as local approximations of the true input/output relationship. ${ }^{7,19)}$ Generally the second-order polynomial function is used for the design variables to represent the response surface. $^{20)}$

$$
y_{\text {predict }}=b_{0}+\sum_{i=1}^{k} b_{i} x_{i}+\sum_{i=1}^{k} b_{i i} x_{i i}^{2}+\sum_{i=1}^{k-1} \sum_{j=2}^{k} b_{i j} x_{i} x_{j}
$$

where $x_{1}, x_{2}, \cdots, x_{k}$ are the design variables which affect the response, $b_{i}(i=1,2, \cdots, k)$ are the coefficients of the regression function, and $y_{\text {predict }}$ is the predicted value from the regression function.

Sensitivity analysis was performed to identify sensible design variables and parameters before implementation of the approximation functions. ${ }^{5,21)}$ Based on an empirical and theoretical equation relationship, a set of design variables for the specific response parameter was selected for sensitivity analysis. Then, RSM was iteratively performed using the most influential design variables from the sensitivity analysis. The accuracy of the approximation model was checked with adjusted $R^{2}$. The typical range was between 0.9 and 1.0. ${ }^{19)}$ The approximation function with adjusted $R^{2}$ values 


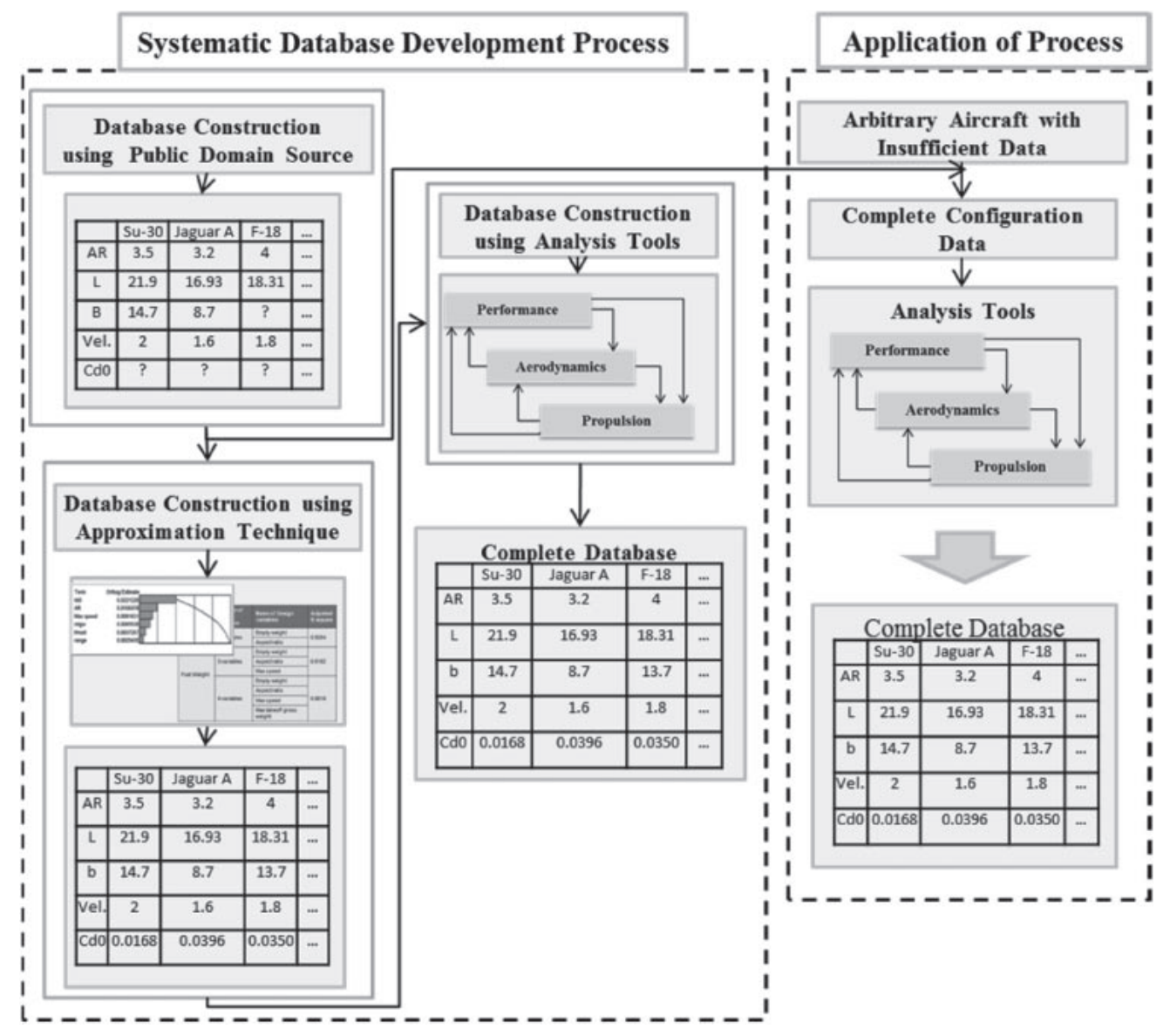

Fig. 2. Database development process.

was obtained. The detailed flow process is described in Fig. 3.

$$
R_{\mathrm{adj}}^{2}=1-\frac{\mathrm{SSE} /(n-p)}{\mathrm{SST} /(n-1)}
$$

where SSE and SST are the error sum of squares and total sum of squares, respectively. The variable, $n$, is the number of experimental points and $p$ is the number of response function coefficients.

Missing data in fuel weight, leading-edge sweep angle, and SFC with afterburner and without afterburner were predicted with the approximation function. The process of developing fuel weight approximation using RSM is described below. Table 1 describes the number of design variables for the approximation function and their adjusted $R^{2}$ values for fuel weight. The priorities of described design variables were obtained from sensitivity analysis.

After comparison of these three cases, the set of design variables with the highest adjusted $R^{2}$ value was chosen to create the approximation function. Thus, the empty weight and aspect ratio became design variables for constructing the fuel weight approximation function.

$$
\text { fuel weight }=f(\text { empty weight, aspect ratio) }
$$

Validations of the approximate values for fuel weight for the selected aircraft are shown in Table 2. Similarly, approximation functions for leading-edge sweep angle, and specific

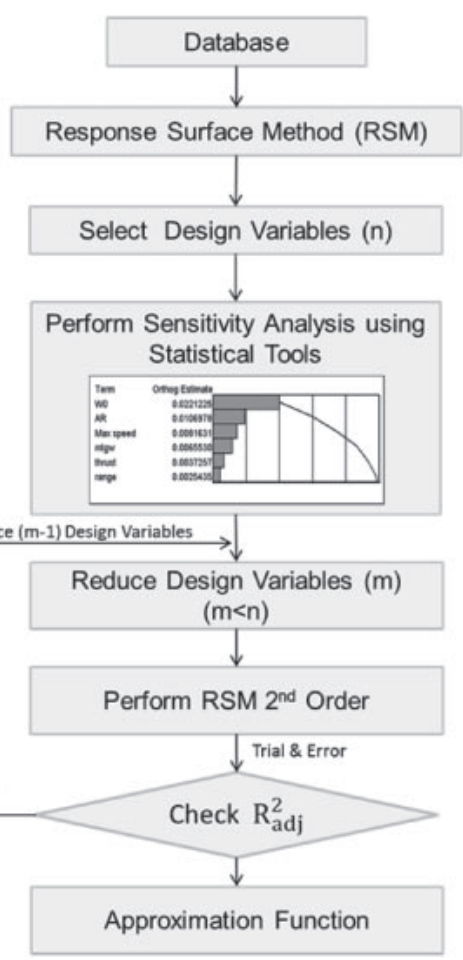

Fig. 3. Approximation library construction flowchart. 
Table 1. Comparison of adjusted $R^{2}$ for fuel weight.

\begin{tabular}{cclc}
\hline \multirow{2}{*}{ Response } & $\begin{array}{c}\text { Number of } \\
\text { design variables }\end{array}$ & $\begin{array}{l}\text { List of design } \\
\text { variables }\end{array}$ & $\begin{array}{c}\text { Adjusted } \\
R^{2}\end{array}$ \\
\hline Fuel weight & 2 variables & $\begin{array}{l}\text { Empty weight } \\
\text { Aspect ratio }\end{array}$ & 0.92 \\
\cline { 2 - 4 } & 3 variables & $\begin{array}{l}\text { Empty weight } \\
\text { Aspect ratio } \\
\end{array}$ & 0.91 \\
& Max. speed & \\
\cline { 2 - 4 } & Empty weight & 0.90 \\
& $\begin{array}{l}\text { Aspect ratio } \\
\text { Max. speed }\end{array}$ & \\
& MTGW & \\
&
\end{tabular}

Table 2. Validation of approximate values for fuel weight.

\begin{tabular}{lccccr}
\hline \multicolumn{1}{c}{ Name } & AR & $\begin{array}{c}W_{\text {empty }} \\
(\text { lb })\end{array}$ & $\begin{array}{c}W_{\text {fuel }}(\text { lb) } \\
\text { (real data) }\end{array}$ & $\begin{array}{c}W_{\text {fuel }}(\mathrm{lb}) \\
\text { (approximated data) }\end{array}$ & Err.\% \\
\hline AIDC F-Ck-1 & 3.66 & 14299.14 & 12300.81 & 10382.13 & $15.59 \%$ \\
Su-30 & 3.49 & 39021.81 & 36637.62 & 31686.09 & $13.51 \%$ \\
F1 & 2.82 & 16314.22 & 14126.67 & 13373.93 & $5.32 \%$ \\
\hline
\end{tabular}

Table 3. Validation of approximation function.

\begin{tabular}{lccc}
\hline \multicolumn{1}{c}{ Approximation function } & Real data & Approximated data & Err. \% \\
\hline Leading-edge sweep angle & 33.01 & 31.10 & $5.78 \%$ \\
SFC with afterburner & 1.92 & 1.86 & $3.12 \%$ \\
SFC without afterburner & 0.81 & 0.82 & $2.50 \%$ \\
\hline
\end{tabular}

fuel consumption (SFC) with afterburner and without afterburner were also applied to predict missing data in the developed database. Validation of these functions can be seen in Table 3.

\subsection{Database construction using analysis tools}

Analysis based on systematic empirical and theoretical equations for the performance, aerodynamics and propulsion of aircraft was conducted. By this means, aircraft data can be calculated quickly and with reasonable accuracy from a minimal set of known parameters. All analysis codes were implemented with VBA. This allows the functions to be used smoothly and in a user-friendly manner by setting the input values in the functions like a spreadsheet's built-in function. ${ }^{11,13)}$

The aircraft's component weights were calculated using configuration data. Total aircraft empty weight was obtained by summing up the component weights. Statistically-derived weight estimation equations for fighter and attack aircraft were implemented. The weight components were wing weight, vertical tail weight, fuel system and tank weight, engine weight, engine selection weight, engine mount weight, etc. Total aircraft weight was calculated by summing the aircraft empty weight, fuel weight and payload weight.

Lift coefficient and drag coefficient were calculated in an aerodynamic analysis module. Parasite drag and induced drag were also calculated. The component build-up method was used in $C_{d 0}$ calculation. Maximum climb angle, climb rate, limited bank angle, maximum turning rate, stall speed and range calculations were considered and implemented in the performance analysis. Specific fuel consumption and

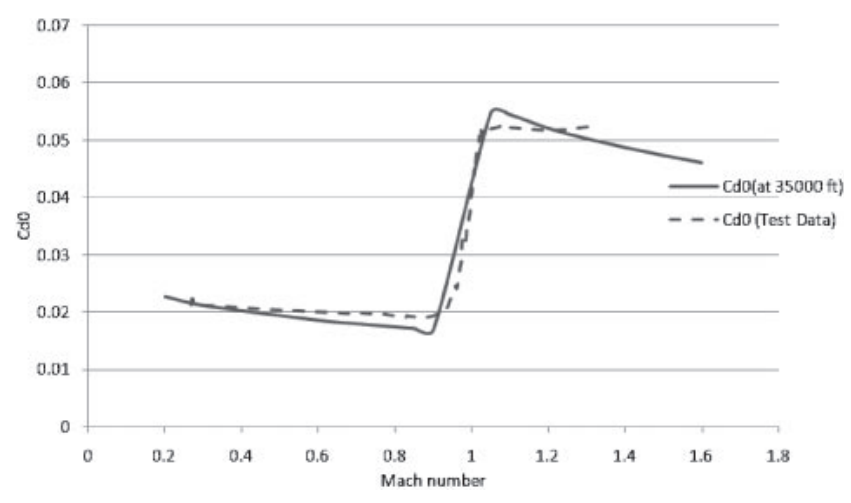

Fig. 4. Comparison of $C_{d 0}$ for generic fighter aircraft.

Table 4. Validation of analysis results.

\begin{tabular}{ccccc}
\hline Name & Parameter & $\begin{array}{c}\text { Calculated } \\
\text { data }\end{array}$ & Test data & Err. \% \\
\hline $\begin{array}{c}\text { Generic } \\
\text { fighter } \\
\text { aircraft }\end{array}$ & Stall speed (knot) & $\begin{array}{c}107.89 \\
\text { (50\% of fuel, } \\
\text { plain flap) }\end{array}$ & $\begin{array}{c}110.01 \\
(50 \% \text { of fuel) }\end{array}$ & $1.93 \%$ \\
F-16 C & $\begin{array}{c}\text { Max. climb angle } \\
\text { (deg) }\end{array}$ & 34.37 & 33.91 & $1.36 \%$ \\
$\begin{array}{c}\text { Generic } \\
\text { fighter } \\
\text { aircraft }\end{array}$ & $\begin{array}{c}\text { Max. rate of climb } \\
\text { (ft/s) }\end{array}$ & 544.81 & 570.76 & $4.57 \%$ \\
$\begin{array}{c}\text { F-22 } \\
\text { Turning rate (deg/s) } \\
\text { (sustained turn rate) }\end{array}$ & 19.49 & 20.07 & $2.89 \%$ \\
$\begin{array}{c}\text { Generic } \\
\text { fighter } \\
\text { aircraft }\end{array}$ & $\begin{array}{c}\text { Fuel flow } \\
\text { (with maximum thrust) } \\
\text { (without afterburner) }\end{array}$ & & & \\
\hline & 9656.25 & 9659.28 & $0.03 \%$ \\
\hline
\end{tabular}

fuel flow were also calculated from empirical equations. The analysis codes produced results in very close agreement with published data. Validations are also described in this section. The validation of $C_{d 0}$ for generic fighter aircraft is illustrated in Fig. 4.

The validation of the analysis code for the performance, propulsion and aerodynamics parameters of the selected aircraft is shown in Table 4.

A database for 43 different types of fighter and attack aircraft with complete information such as general configuration, weight information, performance, aerodynamics and propulsion data was constructed using the database development process described in this study. The next section describes the efficient application of the database as a decision model to aid initial design consideration.

\section{Decision-making Modeling Process}

In the decision-making modeling process, decision models were used to derive an initial aircraft configuration from the fighter and attack aircraft database to assist decisions of designers. This process transforms large amounts of data into meaningful patterns and rules. The detailed process is described in Fig. 5. A predicted initial aircraft configuration was used in the optimization process. The decision models were generated by data mining and an approximation technique according to data type. ${ }^{22)}$ Data mining is a computational technique that computes decision models useful for 


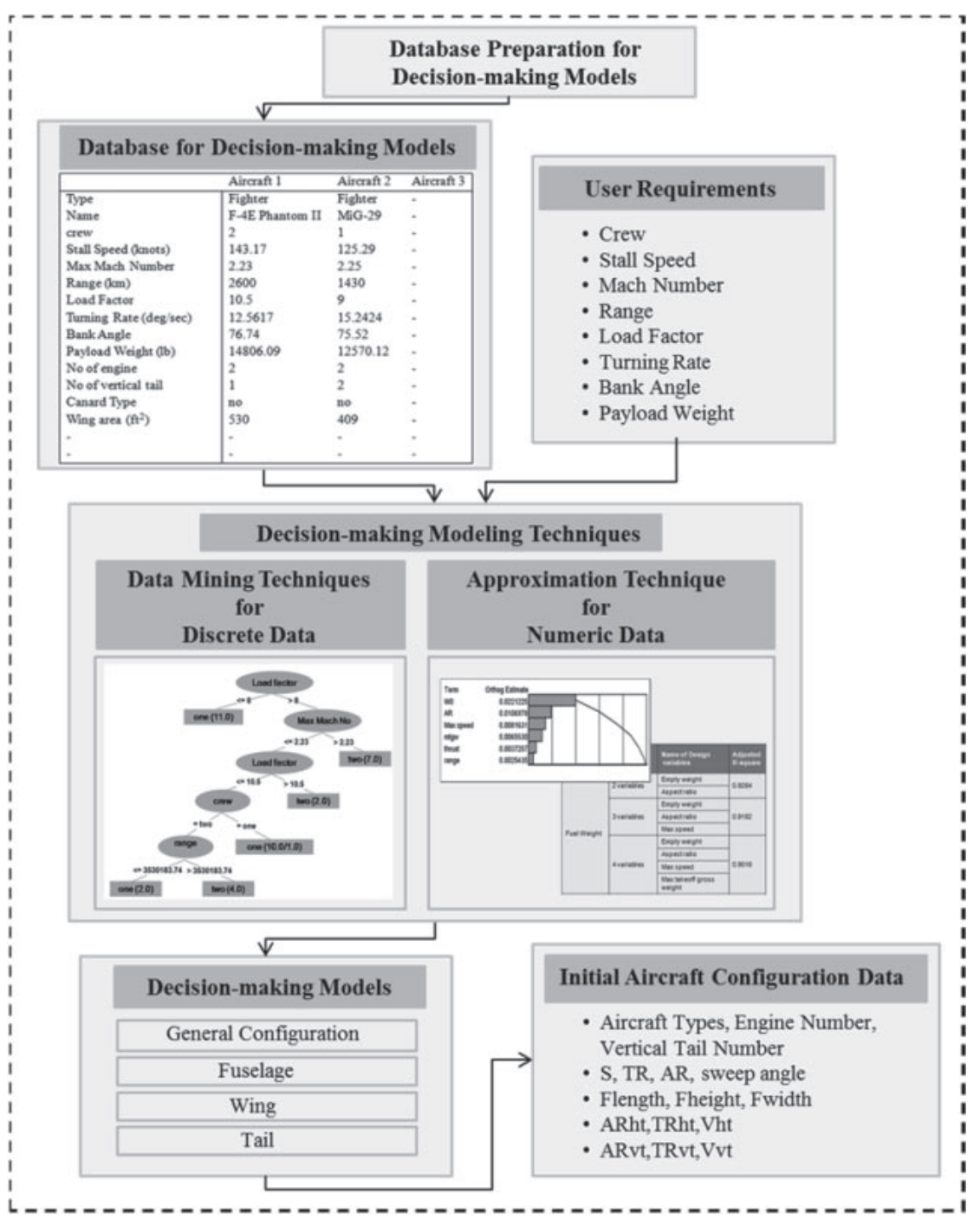

Fig. 5. Decision-making modeling process.

classifying and predicting the behavior of new data. ${ }^{23,24)}$ Data mining techniques can perform well with discrete types of data. On the other hand, approximation techniques with sensitivity analysis can handle numeric data types more accurately.

\subsection{Database for decision-making model}

In order to create a good decision model, an existing data set with a known output was constructed and decision models were built from the database. Aircraft configurations were predicted from the performance of the aircraft. To find data relationships between performance parameters and configurations, the database which included both parts was reclassified. A limited number of performance parameters were accessed in this research because of the small capacity of the database. A list of data included in the reclassified database for the decision-making model is provided in Table 5.

\subsection{Implementation of decision-making model}

The reclassified database allowed empirical decision models to be generated using two techniques according to data type. The constructed decision models are listed in Table 6.

\subsubsection{Implementation by data mining techniques}

Data mining analysis includes algorithms such as regres- sion, classification, clustering and nearest neighbor. A classification algorithm, also known as classification tree or decision tree, was utilized in this study to realize the decisionmaking model. This algorithm can create a step-by-step guide for how to determine and predict the output for new data instances. Weka data mining software was used for construction of the decision models. Among several data mining algorithms, the J48 decision tree algorithm was chosen to implement a decision tree model. These decision models also perform selection of the most related attributes in the process.

Generating a decision tree model for vertical tail number selection based on the prepared database is shown in Fig. 6. As shown in the figure, the first splitting attribute was stall speed. If the stall speed is less than 134.54, that branch will give one result. If the stall speed is greater than 134.54, two new branches split at that node. By following these branches the final decision is obtained from the decision tree. Using this decision model, vertical tail numbers can be predicted by setting the decision factors as input for new aircraft. Other predicted general arrangements provided by the data mining technique for discrete data are described in Table 11. 
Table 5. Database for decision-making model.

\begin{tabular}{|c|c|c|c|c|c|}
\hline & Description & Unit & A1 & $\mathrm{A} 2$ & A3 \\
\hline \multirow{10}{*}{$\begin{array}{l}\text { Performance } \\
\text { data }\end{array}$} & Name & - & F-4E & MiG-29 & - \\
\hline & & & Phantom II & & \\
\hline & Crew & - & 2 & 1 & 一 \\
\hline & Stall speed & knot & 143.17 & 125.29 & 一 \\
\hline & Max. Mach number & - & 2.23 & 2.25 & 一 \\
\hline & Range & $\mathrm{km}$ & 2600 & 1430 & 一 \\
\hline & Load factor & - & 10.50 & 9.00 & - \\
\hline & Turning rate & $\mathrm{deg} / \mathrm{s}$ & 12.56 & 15.24 & 一 \\
\hline & Bank angle & deg & 76.74 & 75.52 & 一 \\
\hline & Payload weight & $\mathrm{lb}$ & 14806.09 & 12570.12 & 一 \\
\hline \multirow{18}{*}{$\begin{array}{l}\text { Configuration } \\
\text { data }\end{array}$} & Aircraft type & - & Fighter & Fighter & - \\
\hline & Engine number & - & 2 & 2 & - \\
\hline & Vertical tail number & - & 1 & 2 & 一 \\
\hline & $\begin{array}{l}\text { Canard } \\
\text { (with or without) }\end{array}$ & - & no & no & 一 \\
\hline & Engine number & - & 2 & 2 & 一 \\
\hline & Wing area & $\mathrm{ft}^{2}$ & 530 & 409 & 一 \\
\hline & Sweep angle & deg & 45 & 42 & 一 \\
\hline & Aspect ratio & - & 2.77 & 3.39 & 一 \\
\hline & Taper ratio & - & 0.18 & 0.31 & 一 \\
\hline & Fuselage length & $\mathrm{ft}$ & 59.27 & 46.56 & 一 \\
\hline & Fuselage width & $\mathrm{ft}$ & 4.15 & 3.19 & 一 \\
\hline & Fuselage height & $\mathrm{ft}$ & 5.92 & 5.17 & 一 \\
\hline & HT aspect ratio & - & 2.58 & 2.42 & - \\
\hline & HT taper ratio & - & 0.34 & 0.73 & 一 \\
\hline & $\begin{array}{l}\text { HT volume } \\
\text { coefficient }\end{array}$ & - & 0.13 & 0.19 & - \\
\hline & VT aspect ratio & - & 0.48 & 0.34 & 一 \\
\hline & VT taper ratio & - & 0.35 & 0.24 & 一 \\
\hline & $\begin{array}{l}\text { VT volume } \\
\text { coefficient }\end{array}$ & - & 0.02 & 0.06 & - \\
\hline
\end{tabular}

Table 6. List of decision models.

\begin{tabular}{lc}
\hline Implementation by data mining techniques for discrete data \\
\hline General aircraft configuration & $\begin{array}{c}\text { Aircraft types, engines number, } \\
\text { vertical tail number }\end{array}$ \\
\hline Implementation by approximation techniques for numeric data \\
\hline Wing & $\begin{array}{c}\text { Wing area, sweep angle, aspect ratio, } \\
\text { taper ratio }\end{array}$ \\
Fuselage & Fuselage length, fuselage width, \\
fuselage height \\
Horizontal tail & HT aspect ratio, HT taper ratio, HT \\
& volume coefficient \\
Vertical tail & VT aspect ratio, VT taper ratio, VT \\
& volume coefficient \\
\hline
\end{tabular}

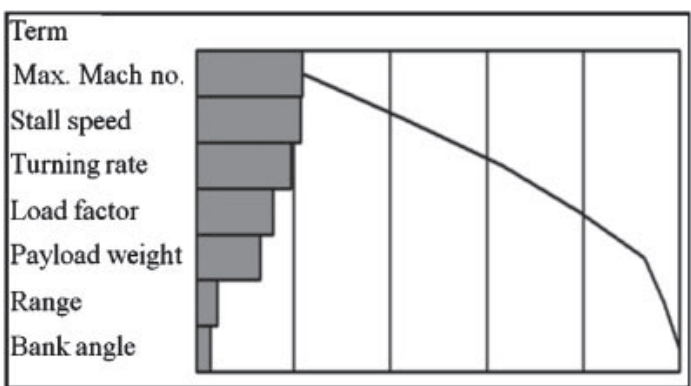

(a) Sweep angle sensitivity analysis

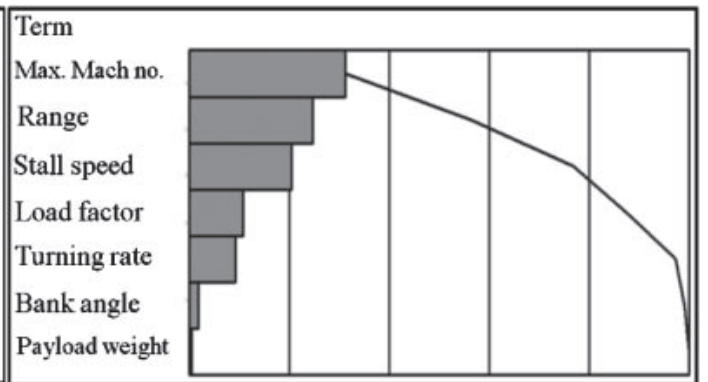

(b) Wing area sensitivity analysis

Fig. 7. Sensitivity analysis.

\subsubsection{Implementation by approximation techniques}

Decision models for wing, fuselage, horizontal tail, and vertical tail with numeric data were implemented by means of approximation techniques. The detailed process was described in section 3.2. Sensitivity analysis was performed before constructing the approximation function. The five most related design variables were chosen for the approximation function for each aircraft configuration using sensitivity analysis. Sensitivity analyses for sweep angle and wing area are described in Fig. 7. According to Fig. 7(a), maximum Mach number is mainly related to sweep angle and stall speed is secondly related to sweep angle. In Fig. 7(b), maximum Much number and range are firstly and secondly related with wing area, respectively. The predicted results for initial air- craft configuration by the approximation technique for numeric data are also described in Table 11.

\section{Case Study}

In order to demonstrate the benefits of the database development process and its application in developing an efficient decision-making model for aircraft initial design, a case study was carried out.

\subsection{Database prediction for new aircraft using the da- tabase development process}

To test the feasibility, effectiveness and speed of the database development process, a new aircraft not included in the database with insufficient data was selected. The selected air- 
Table 7. Database construction using public domain sources for the Mitsubishi ATD-X.

\begin{tabular}{lc}
\hline Database construction using public domain sources & \\
\hline Type & Fighter \\
Name & Mitsubishi ATD-X \\
Country & Japan \\
Max G & $-3 /+9$ \\
Empty weight (lb) & 26455.47 \\
Thrust (lb) & 22046 \\
Wing area (ft $\left.{ }^{2}\right)$ & 377.55 \\
Wing span (ft) & 29.85 \\
Cruise altitude (ft) & 35000 \\
Thrust (lb) (with afterburner) & 33069 \\
Max. speed (knot) (sea level) & 687.78 \\
\hline
\end{tabular}

Table 8. Database construction using approximation techniques for the Mitsubishi ATD-X

\begin{tabular}{lr}
\hline Database construction using approximation techniques & \\
\hline Fuel weight (lb) & 18912.42 \\
Leading-edge sweep angle (deg) & 54.20 \\
SFC (lb/lbf-hr) (without afterburner) & 0.78 \\
SFC (lb/lbf-hr) (with afterburner) & 2.05 \\
Cruise speed (knot) & 1043.14
\end{tabular}

Table 9. Database construction using analysis tools for the Mitsubishi ATD-X.

\begin{tabular}{lr}
\hline Database construction using analysis tools & \\
\hline Min. speed (knot) & 203.05 \\
$C_{d 0}$ (at $\left.M=0.8,10000 \mathrm{ft}\right)$ & 0.01 \\
Maximum climb angle (deg) & 41.94 \\
Maximum turning rate (ft/s) & 16.13 \\
Limit by bank angle (deg) & 75.52 \\
Fuel flow (lbm/hr) (without afterburner) & 17195.88 \\
$\quad$ (at maximum thrust) & \\
Fuel flow (lbm/hr) (with afterburner) & 67791.45 \\
$\quad$ (at maximum thrust)
\end{tabular}

craft was the Mitsubishi ATD-X. ${ }^{15}$ ) This is a prototype fifthgeneration jet fighter. Table 7 shows the database construction from public domain sources for the Mitsubishi ATD-X aircraft.

Using the approximation function implemented from the constructed database, the parameters described in Table 8 can be predicted.

The aerodynamics, performance and propulsion parameters for the Mitsubishi ATD-X aircraft were computed using the analysis tools. The data is described in Table 9.

Finally, a design database for a new fighter aircraft, Mitsubishi ATD-X, was developed successfully and efficiently using the implemented database development process.

\subsection{Design optimization process for fighter aircraft}

A case study for a design process was performed for the F-CK-1 Ching-kuo aircraft. ${ }^{15)}$ It is a fourth-generation jet fighter aircraft.

\subsubsection{Prediction of initial aircraft configuration}

In the case study of the decision-making model, performance requirements were set to be equal to the performance of existing F-CK-1 aircraft in the implemented database in order to assess the quality of results. The set of performance
Table 10. Input for decision models.

\begin{tabular}{lcc}
\hline \multicolumn{1}{c}{ Description } & Unit & F-CK-1 aircraft \\
\hline Crew & - & 2 \\
Stall speed & $\mathrm{knot}$ & 130 \\
Max. Mach number & - & 1.8 \\
Range & $\mathrm{km}$ & 1100 \\
Load factor & - & 9.1 \\
Turning rate & $\mathrm{deg} / \mathrm{s}$ & 12 \\
Bank angle & $\mathrm{deg}$ & 75.6 \\
Payload weight & $\mathrm{lb}$ & 400 \\
\hline
\end{tabular}

Table 11. Output of decision models.

\begin{tabular}{|c|c|c|c|c|c|c|}
\hline $\begin{array}{l}\text { Data } \\
\text { type }\end{array}$ & Group & Description & Unit & $\begin{array}{c}\text { Decision } \\
\text { models } \\
\text { output }\end{array}$ & $\begin{array}{l}\text { F-CK-1 } \\
\text { aircraft }\end{array}$ & Err. $\%$ \\
\hline $\begin{array}{l}\text { Discrete } \\
\text { data }\end{array}$ & $\begin{array}{l}\text { General } \\
\text { aircraft } \\
\text { configuration }\end{array}$ & $\begin{array}{l}\text { Aircraft type } \\
\text { Engine number } \\
\text { Vertical tail } \\
\text { number }\end{array}$ & - & $\begin{array}{c}\text { Fighter } \\
2 \\
1\end{array}$ & $\begin{array}{c}\text { Fighter } \\
2 \\
1\end{array}$ & - \\
\hline \multirow[t]{4}{*}{$\begin{array}{c}\text { Numeric } \\
\text { data }\end{array}$} & Wing & $\begin{array}{l}\text { Wing area } \\
\text { Sweep angle } \\
\text { Aspect ratio } \\
\text { Taper ratio } \\
\end{array}$ & $\begin{array}{c}\mathrm{ft}^{2} \\
\mathrm{deg} \\
- \\
-\end{array}$ & $\begin{array}{r}270.59 \\
41.31 \\
3.78 \\
0.28 \\
\end{array}$ & $\begin{array}{r}260.00 \\
37.00 \\
3.69 \\
0.26 \\
\end{array}$ & $\begin{array}{r}3.91 \\
10.43 \\
2.38 \\
7.14 \\
\end{array}$ \\
\hline & Fuselage & $\begin{array}{l}\text { Fuselage length } \\
\text { Fuselage width } \\
\text { Fuselage height }\end{array}$ & $\begin{array}{l}\mathrm{ft} \\
\mathrm{ft} \\
\mathrm{ft}\end{array}$ & $\begin{array}{r}38.20 \\
9.21 \\
5.54\end{array}$ & $\begin{array}{r}33.75 \\
10.08 \\
4.98\end{array}$ & $\begin{array}{r}11.65 \\
-9.45 \\
10.11\end{array}$ \\
\hline & $\begin{array}{l}\text { Horizontal } \\
\text { tail }\end{array}$ & $\begin{array}{l}\text { HT aspect ratio } \\
\text { HT taper ratio } \\
\text { HT volume } \\
\text { coefficient }\end{array}$ & $\begin{array}{l}- \\
-\end{array}$ & $\begin{array}{l}3.44 \\
0.34 \\
0.33\end{array}$ & $\begin{array}{l}3.78 \\
0.30 \\
0.37\end{array}$ & $\begin{array}{r}-9.88 \\
11.76 \\
-12.12\end{array}$ \\
\hline & Vertical tail & $\begin{array}{l}\text { VT aspect ratio } \\
\text { VT taper ratio } \\
\text { VT volume } \\
\text { coefficient }\end{array}$ & $\begin{array}{l}- \\
-\end{array}$ & $\begin{array}{l}0.48 \\
0.28 \\
0.06\end{array}$ & $\begin{array}{l}0.49 \\
0.27 \\
0.05\end{array}$ & $\begin{array}{r}-2.08 \\
3.57 \\
13.33\end{array}$ \\
\hline
\end{tabular}

data is described in Table 10. The results of decision-making models are shown in Table 11. These results matched well the configuration of the F-CK-1 aircraft.

\subsubsection{Design formulation}

In this study, the objective function was to minimize the maximum take-off gross weight subject to performance requirements, and this was a function of the design variables. Decision-making models and analysis tools were implemented by means of spreadsheets and VBA for simple and efficient handling and updating of the information. Thus, the optimization process was performed in a spreadsheet. An optimizer was applied with the generalized reduced gradient method. ${ }^{25)}$ In order to reduce the computational time, four design variables were chosen, as presented in Table 12. Constraints are described in Table 13. In order to assess the quality of the results, the performance constraints were set to be equal to the performance of the AIDC F-CK-1 Ching-kuo aircraft.

The aircraft included in the developed database were for the period 1950 to 2010 . Average values were analyzed by decade for each aircraft parameter. The approximated historical trends and $R^{2}$ values are described in Fig. 8. Fudge factor, $0.976,0.951$ and 0.980 for empty weight, range and stall speed, were derived from the approximated historical trends to correct aircraft parameters during the analysis. 


\subsubsection{Optimization results and discussion}

The optimizer was set to minimize the maximum take-off gross weight while meeting performance constraints equal to the performance of the AIDC F-CK-1 Ching-kuo aircraft.

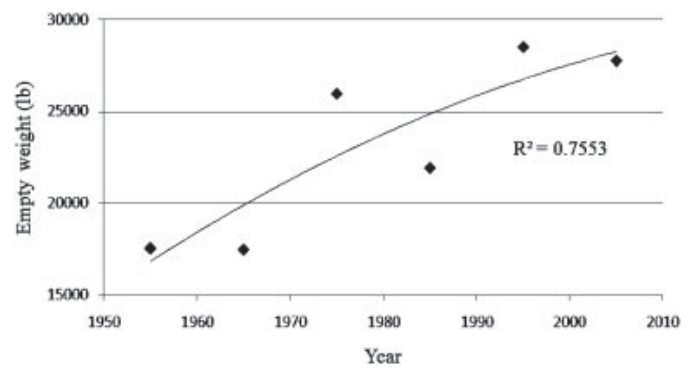

(a) Empty weight

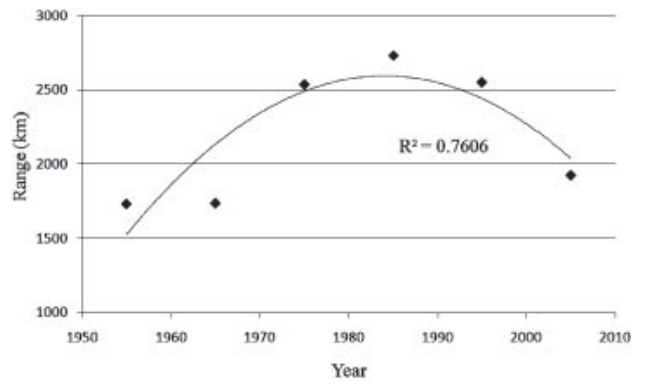

(b) Range

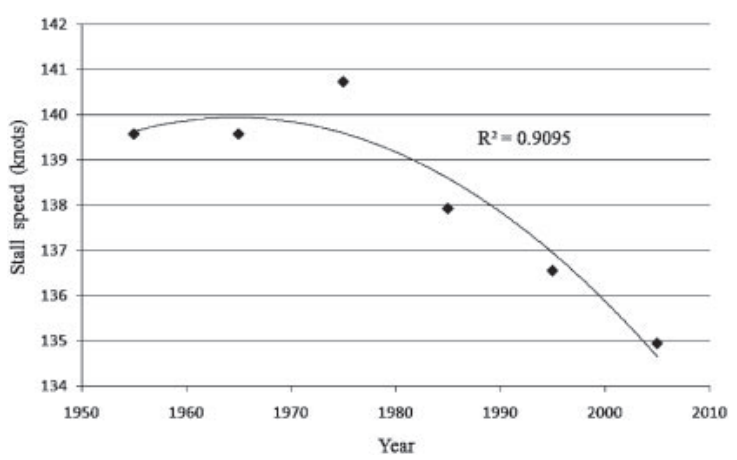

(c) Stall speed
The optimization process was carried out for two cases. The first optimization process was performed using initial aircraft configurations that were predicted by the decision models with the same target performance attributes as the F-CK-1 aircraft. The predicted initial aircraft configurations are shown in Table 11. The second optimization process was carried out setting the initial aircraft configuration randomly. The design generated by the optimizer for the two cases can be seen in Table 14. A comparison of the convergence history for the two cases is described in Fig. 9. The optimization process with smart prediction of the initial design by decision model generated the results in less iteration than the optimization process with random selection of the initial design.

This design process and its systematical database development process can also be applied for different aircraft types, such as commercial transport aircraft and general aviation aircraft. In construction of the decision models, a limited set of performance data is used to predict configuration. More performance data is needed for better prediction by physical and data relationships. Additional configurations such as location and detail information of wing, horizontal tail and vertical tail need to be inserted into the database.

Table 12. Design variables.

\begin{tabular}{llccc}
\hline & \multicolumn{1}{c}{ Description } & Unit & $x_{l b}$ & $x_{u b}$ \\
\hline 1 & Wing area & $\mathrm{ft}^{2}$ & 226 & 375 \\
2 & Sweep angle & $\mathrm{deg}$ & 35.00 & 55.50 \\
3 & Wing aspect ratio & - & 1.75 & 5.33 \\
4 & Wing taper ratio & - & 0.10 & 0.56 \\
\hline
\end{tabular}

Table 13. Design constraints.

\begin{tabular}{|c|c|c|c|c|}
\hline & Description & Unit & Goal & Condition \\
\hline $\mathrm{C} 1$ & Empty weight & $\mathrm{lb}$ & $\leq 14299$ & Weight \\
\hline $\mathrm{C} 2$ & Range & $\mathrm{km}$ & $\geq 1100$ & Performance (max. range) \\
\hline $\mathrm{C} 3$ & Climb rate & $\mathrm{ft} / \mathrm{s}$ & $\geq 300$ & Performance (at climb condition) \\
\hline $\mathrm{C} 4$ & Turning rate & $\mathrm{deg} / \mathrm{s}$ & $\geq 12$ & Performance (sustained turn rate) \\
\hline C5 & Stall speed & knot & $\leq 130$ & Performance (plain flap) \\
\hline C6 & Turning radius & $\mathrm{ft}$ & $\leq 1526$ & Performance (at max. load factor) \\
\hline
\end{tabular}

Fig. 8. Approximated historical trends.

Table 14. Optimization results.

\begin{tabular}{|c|c|c|c|c|c|c|}
\hline & Description & Unit & $\begin{array}{l}\text { Initial design } \\
\text { using decision } \\
\text { model }\end{array}$ & $\begin{array}{c}\text { Optimization } \\
\text { results (Case } 1 \text { ) }\end{array}$ & $\begin{array}{l}\text { Initial design } \\
\text { using random } \\
\text { selection }\end{array}$ & $\begin{array}{l}\text { Optimization } \\
\text { results (Case 2) }\end{array}$ \\
\hline & Iteration number & & & 12 & & 16 \\
\hline Objective function & MTGW & $\mathrm{lb}$ & 26676.49 & 25090.12 & 26976.31 & 24937.69 \\
\hline \multirow[t]{4}{*}{ Design variables } & Wing area & $\mathrm{ft}^{2}$ & 270.59 & 261.94 & 291.00 & 265.43 \\
\hline & Sweep angle & deg & 41.31 & 53.00 & 35.00 & 49.20 \\
\hline & Wing aspect ratio & - & 3.78 & 3.26 & 3.50 & 3.21 \\
\hline & Wing taper ratio & - & 0.28 & 0.21 & 0.30 & 0.25 \\
\hline \multirow[t]{6}{*}{ Constraint } & Empty weight & $\mathrm{lb}$ & 14299 & 12389.29 & 14585.27 & 12559.86 \\
\hline & Range & $\mathrm{km}$ & 1100 & 1119.83 & 1093.64 & 1122.39 \\
\hline & Climb rate & $\mathrm{ft} / \mathrm{s}$ & 300 & 325.43 & 304.19 & 335.75 \\
\hline & Turning rate & $\mathrm{ft} / \mathrm{s}$ & 12 & 14.57 & 13.29 & 14.24 \\
\hline & Stall speed & knot & 130 & 129.02 & 126.91 & 127.76 \\
\hline & Turning radius & $\mathrm{ft}$ & 1526 & 1523.46 & 1858.27 & 1521.04 \\
\hline
\end{tabular}




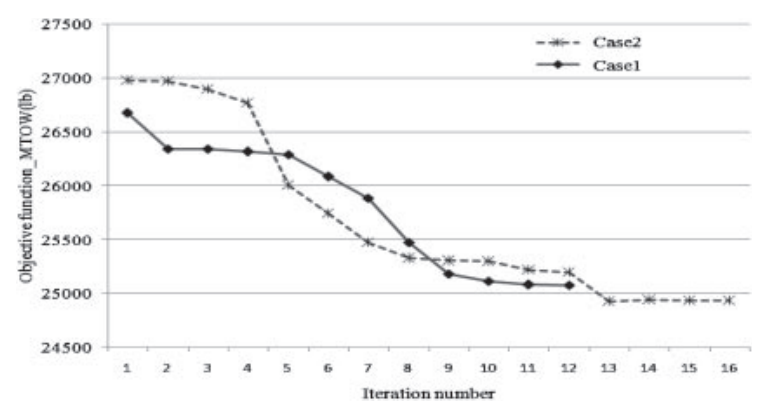

Fig. 9. Convergence history.

\section{Conclusion}

An efficient process for fighter and attack aircraft database development and prediction of initial design configuration using decision models for optimization has been successfully developed. The implemented process began with the development of a fighter and attack aircraft database that was constructed using a systematic process. Configuration, performance, aerodynamics and propulsion data of 43 fighter and attack aircraft were included in the database. This database development methodology can be used to predict data for new fighter and attack aircraft where insufficient data is known. The approximation function and analysis tools have been validated, and the results indicate the accuracy, simplicity and quickness of the developed methodology. The developed database was then implemented to predict the initial configuration of new design concepts using decision models. The process was validated using performance data of existing fighter aircraft as the input for the implemented decision models. Predicted initial configuration data was applied to a design optimization process. Through this process, a new aircraft design with better performance than the reference aircraft was obtained, and it can reduce iteration steps when compared to the process with random selection of the initial design.

\section{Acknowledgments}

This research was supported by the National Research Foundation (NRF), granted number: 2014R1A2A2A01003833, the 2014 KU Brain Pool (Konkuk University), and the corresponding author_Jae Woo Lee, jwlee@konkuk.ac.kr

\section{References}

1) Engelund, W. C., Stanley, D. O., Lepsch, R. A., and McMillin, M. M.: Aerodynamic Configuration Design Using Response Surface Methodology Analysis, AIAA Aircraft Design, Systems, and Operations Meeting, Monterey, CA, 1993.

2) DeLaurentis, D., Mavris, D. N., and Schrage, P. D.: System Synthesis in Preliminary Aircraft Design Using Statistical Methods, 20th Congress of the International Council of the Aeronautical Sciences,
Sorrento, Italy, 1996.

3) Letourneau, S., Famili, F., and Matwin, S.: Data Mining for Prediction of Aircraft Component Replacement, IEEE Intelligent Systems, Special Issue on Data Mining (1999), pp. 59-66.

4) Perrone, L. F., Wiel, F. P., Liu, J., Lawson, B. G., Nicol, D. M., Fujimoto, R. M., Painter, M. K., Erraguntla, M., and Hogg, G. L.: Using Simulation, Data Mining, and Knowledge Discovery Techniques for Optimized Aircraft Engine Fleet Management, 2006 Winter Simulation Conference,WSC, 2006, pp. 1253-1260.

5) Saltelli, A., Chan, K., and Scott, E. M.: Sensitivity Analysis, Wiley Series in Probability and Statistics, John Wiley \& Sons publishers, New York, 2000.

6) Sellar, R. S., Stelmack, M. A., Batill, S. M., and Renaud, J. E.: Response Surface Approximations for Discipline Coordination in Multidisciplinary Design Optimization, Multidisciplinary Design Optimization, 37th AIAA/ASME/ASCE/AHS/ASC Structures, Structural Dynamics and Materials Conference, AIAA, 1996, pp. 96-107.

7) Venter, G., Haftka, R. T., and Starnes, J. H.: Construction of Response Surfaces for Design Optimization Applications, 6th AIAA/NASA/ ISSMO Symposium on Multidisciplinary Analysis and Optimization, Bellevue, WA, AIAA, 1996, pp. 548-564.

8) Raymer, D. P.: Aircraft Design: A Conceptual Approach, 4th Edition, American Institute of Aeronautics and Astronautics, Reston, VA, 2006.

9) Saarlas, M.: Aircraft Performance, John Wiley, USA, 2007.

10) Anderson, J. D. Jr.: Aircraft Performance and Design, McGraw-Hill International, Singapore, 1999.

11) Fylstra, D., Lasdon, L., Watson, J., and Waren, A.: Design and Use of the Microsoft Excel Solver, Interfaces, 28, 5 (1998), pp. 29-55.

12) Mason, A. J. and Dunning, I.: Open Solver: Open Source Optimization for Excel, 45th Annual Conference of the ORSNZ, Operations Research Society of New Zealand, Auckland, 2010.

13) Ragsdale, C. T.: Spreadsheet Modeling and Decision Analysis, 2nd Edition, South-Western Publishing, Cambridge, MA, 1997.

14) Esmaeili, M. and Mosavi, A.: Variable Reduction for Multi-Objective Optimization Using Data Mining Techniques: Application to Aerospace Structures, Proceeding of ICCET, the 2nd IEEE International Conference on Computer Engineering and Technology, Vol. 5, Chengdu, 2010, pp. V5-333-V5-337.

15) Jackson, P.: Jane's All the World's Aircraft, 95th Edition, Jane's Information Group, USA, 2004.

16) Wilkinson, R.: The World's Great Attack Aircraft, W.H. Smith, USA, 1998.

17) Spick, M.: The Illustrated Directory of Fighters, Salamander Books, UK, 2002

18) Gunston, B.: An Illustrated Guide to Modern Fighters and Attack Aircraft, Salamander Books, UK, 1980.

19) Mason, R. L. and Cunst, R. T.: Statistical Design and Analysis of Experiments, 2nd Edition, John Wiley \& Sons, USA, 2003.

20) Montgomery, D. C.: Design and Analysis of Experiments, 5th Edition, John Wiley \& Sons, USA, 2001.

21) Hinkelmann, K. and Kempthorne, O.: Design and Analysis of Experiments, Vol. 2, John Wiley \& Sons, USA, 2005.

22) Witkowski, K.: Data Mining and Visualization of Pareto, Proceedings of 7th European LS-DYNA Conferences Proceeding, 2009.

23) Neufeld, D. and Chung, J.: Enhancing UAV Conceptual Design Using Evolutionary Algorithms and Data Mining, 2006 International Conference in Computational Science and Its Applications (ICCSA 2006), Glasgow, UK, 2006.

24) Witten, I. H. and Eibe, F.: Data Mining: Practical Machine Learning Tools and Techniques, 2nd Edition, Morgan Kaufmann Series in Data Management Systems, USA, 2005.

25) Lasdon, L. S., Waren, A. D., Jain, A., and Ratner, M.: Design and Testing of a Generalized Reduced Gradient Code for Nonlinear Programming, ACM Trans. Mathematical Software, 4, 1 (1978), pp. 34-49. 